\title{
The Importance of Peripheral and Local Blood Analysis for Evaluation of Nitric Oxide and Asymmetric Dimethylarginine Before and After Varicocelectomy
}

\author{
Huseyin Celik ${ }^{1} \cdot$ Ahmet Camtosun $^{1} \cdot$ Ramazan Altintas $^{1}$
}

Received: 26 June 2015 / Accepted: 21 July 2015 / Published online: 30 July 2015

(C) Springer Science+Business Media New York 2015

We read with interest the recently published article in the esteemed Biological Trace Element Research, by Kiziler et al. [1]. The exact pathologic mechanism of varicocele disease was unknown but it has been presumed to be related to the unique angle of the junction of left-side spermatic vein with renal vein coupled with increased hydrostatic pressure or vascular deficiency [2]. Also, the effect of increased reactive oxygen species and nitric oxide (NO) has been implicated as an important role in varicocele. Moreover, in many studies, it was found that NO level had almost nearly double level in the internal spermatic vein than in the peripheral circulation $[3,4]$. However, in the current study, NO was shown as lower in the internal spermatic vein than the peripheral circulation in the related Figure 2 even though there was no statistical comparison done between these parameters. On the other hand, the samples of the femoral vein blood were used instead of the internal spermatic vein blood as postoperative control. As we know from the previous studies, it may not reflect the true outcomes. Cohen et al. and Ito et al. demonstrated that the blood in the internal spermatic vein contained much more detrimental metabolic products, catecholamine, prostaglandins, etc. than the peripheral circulation in varicocele patients $[5,6]$. Moreover, Mostafa et al. reported high level of ROS and decreased level of antioxidants in the internal spermatic vein of varicocele associated infertile patients compared with the peripheral venous blood [4].

Huseyin Celik

drhuseyin@hotmail.com

1 Malatya 44280, Turkey
Asymmetric dimethylarginine (ADMA), an endogenous competitive inhibitor of the nitric oxide synthase (NOS), is known to be associated with endothelial dysfunction, vascular diseases, and atherosclerotic changes. Also, ADMA can uncouple NOS resulting in the formation of superoxide radicals and low-density lipoproteins and oxidized low-density lipoproteins can induce more ADMA formation in oxidative stress [7]. In that case, we expect ADMA level to decrease in the internal spermatic vein after varicocelectomy surgery. In this manner, the present study has contradiction with the previous studies.

\section{References}

1. Kiziler AR, Aydemir B, Guzel S, et al (2015) Comparison of before and after varicocelectomy levels of trace elements, nitric oxide, asymmetric dimethylarginine and malondialdehyde in the seminal plasma and peripheral and spermatic veins. Biol Trace Elem Res 19. doi:10.1007/s12011-015-0303-x

2. Zini A, Boman JM (2009) Varicocele: red flag or red herring? Semin Reprod Med 27:171-178

3. Ozbek E, Cekmen M, Simsek A (2008) Comparison of antioxidant enzyme activity in the internal spermatic vein and brachial veins of patients with infertile varicocele. Int Urol Nephrol 40:679-683

4. Mostafa T, Anis TH, Ghazi S, et al (2006) Reactive oxygen species and antioxidants relationship in the internal spermatic vein blood of infertile men with varicocele. Asian J Androl 8:451-454

5. Cohen MS, Plaine L, Brown JS (1975) The role of internal spermatic vein plasma catecholamine determinations in subfertile men with varicoceles. Fertil Steril 26:1243-1249

6. Ito $\mathrm{H}$, Fuse $\mathrm{H}$, Minagawa $\mathrm{H}$, et al (1982) Internal spermatic vein prostaglandins in varicocele patients. Fertil Steril 37:218-222

7. Aldámiz-Echevarría L, Andrade F (2012) Asymmetric dimethylarginine, endothelial dysfunction and renal disease. Int $\mathrm{J}$ Mol Sci.:11288-311. 